\title{
The Next Black Box of Formative Assessment: A Model of the Internal Mechanisms of Feedback Processing
}

\author{
Angela M. Lui * and Heidi L. Andrade \\ Educational and Counseling Psychology Department, University at Albany-SUNY, Albany, NY, United States
}

OPEN ACCESS

Edited by:

Jason C. Immekus, University of Louisville, United States

Reviewed by:

Anna C Brady,

Georgia Southern University,

United States

Ignacio Máñez,

University of Valencia, Spain

*Correspondence:

Angela M. Lui

angela.lui@cuny.edu

Specialty section:

This article was submitted to Educational Psychology,

a section of the journal

Frontiers in Education

Received: 01 August 2021 Accepted: 10 January 2022

Published: 15 February 2022

Citation:

Lui AM and Andrade HL (2022) The Next Black Box of Formative Assessment: A Model of the Internal Mechanisms of Feedback Processing.

Front. Educ. 7:751548

doi: 10.3389/feduc.2022.751548
In this theoretical paper, we shift the attention from feedback as something given to feedback as something received. After Black and Wiliam shined a light into the black box of the classroom and identified formative assessment as a way to raise standards of achievement, a large body of research revealed the influence of feedback on learning. Not all such influences were positive, however, which created a need for closer examinations of the nature of feedback. In addition, recent scholarship on assessment as the co-regulation of learning reveals the importance of understanding how students process and use feedback. We present a model of the internal mechanisms of feedback processing that represents hypothesized ways in which initial motivational states drive how students respond to feedback, as well as the cognitive and affective mechanisms of assessment information processing. We first synthesize a review of existing models and then describe our model in detail, emphasizing the internal mechanisms of feedback processing: initial motivational states, emotions elicited by and interpretations of feedback, and decision-making. The paper concludes with implications for the model's use as a framework for empirical studies that could contribute to the nascent field of research on classroom assessment as the co-regulation of learning.

Keywords: formative assessment, formative feedback, internal mechanisms of feedback processing, responses to feedback, affective and cognitive processes, emotions, interpretations, decision making

\section{INTRODUCTION}

Formative assessment in education, or assessment for learning (Stiggins, 2005), has been a growing field since 1998 when Black and Wiliam introduced fellow researchers and practitioners to the black box of the classroom. They used the term black box to emphasize the fact that what happened in most classrooms was largely unknown: All we knew was that some inputs (e.g., teachers, resources, standards, and requirements) were fed into the box, and specific outputs (e.g., more knowledgeable and competent students, acceptable levels of achievement) could follow. They wanted to know what was happening inside the black box and what new inputs would produce better outputs. Upon reviewing over 250 articles related to formative assessment, Black and Wiliam found evidence that this promising new conception of assessment-formative assessment-could raise standards and increase student learning by yielding actionable information on learning as it occurs. The primary purpose of formative assessment is to collect evidence of students' current levels of understanding to inform further instruction by teachers and/or next steps for students to take to enhance their learning (Wiliam, 2010). 
Research on formative assessment has expanded a great deal since Black and Wiliam's review. Much but not all of that research supports claims of its effectiveness. Inconsistent findings on the effects of formative assessment and feedback have led to the emergence of the next black box that will be explored here: understanding how students interpret and subsequently use feedback that they receive from an external source. This view shifts from treating feedback as something given to something received. We begin with a brief review of the research on formative assessment, highlighting the inconsistent findings regarding the effects of formative assessment on achievement. Then we propose students' responses to feedback as an explanation for the inconsistencies and enter the next black box with a selective review of the literature on conceptions, perceptions, and emotions related to feedback. After that, we review models that inform the design of our new model. We end with a description and discussion of the model that operationalizes the internal mechanisms of feedback processing.

\section{RESEARCH ON THE BLACK BOX OF FORMATIVE ASSESSMENT AND FEEDBACK}

Black and Wiliam (1998) review spurred a great deal of research on the effects of formative assessment on student achievement in various educational settings and disciplines. Several influential reviews have found an overall positive association between formative assessment and student learning. For example, Kingston and Nash (2011) found a modest, weighted mean effect size of 0.20 of formative assessment on learning in a meta-analysis. The metaanalysis by Graham et al. (2015), which examined true and quasi-experimental design studies on formative assessment of writing in grades one to eight, categorized the source of formative feedback in terms of teachers, peers, self, and computers, and yielded average weighted effect sizes of $0.87,0.58,0.62$, and 0.38 , respectively. Other non-metaanalytic reviews (Wiliam et al., 2004; Shute, 2008; Bennett, 2011; Filsecker and Kerres, 2012; McMillan et al., 2013) echoed the findings: Improvements in student learning can be meaningful, if not consistently as large as reported in early studies, and the positive effects hold across different age groups, core school subjects, and countries.

Feedback for students is a key element of formative assessment (Black and Wiliam, 2009). Feedback is most useful when there is an influence on future performance, or at least an attempt to use the information from feedback to improve learning (Ramaprasad, 1983; Sadler, 1989; Black and Wiliam, 1998; Wiliam, 2011). In addition, research suggests that effective feedback is descriptive and constructive (not graded, nor focused on the person), specific and oriented toward targeted learning goals, delivered in a supportive and timely manner, and communicated in a way that students can understand (Hattie and Timperley, 2007; Shute, 2008; Andrade, 2013; Andrade, 2016). Feedback should close the gap between where students are and where they need to be (Kulhavy, 1977; Ramaprasad, 1983; Butler and Winne, 1995; Hattie and Timperley, 2007), ultimately improving their academic achievement.

In a review of 12 meta-analyses on feedback in classrooms, Hattie (2009) concluded that, under the right conditions, feedback in a formative context can contribute significantly to students' achievement, with an average effect size of 0.73 . Consistent with Hattie, other reviews and meta-analyses have reported that feedback tends to have a positive association with learning and achievement (Hattie and Timperley, 2007; Shute, 2008; Lipnevich and Smith, 2009a; Wiliam, 2010; 2013; RuizPrimo and Li, 2013; Van der Kleij et al., 2015; Wisniewski et al., 2020). However, negligible and even negative relationships have also been noted (Bennett, 2011). For example, Kluger and DeNisi (1996) reported a mean effect size of 0.41 for formative feedback on performance, but $38 \%$ of these effects were negative. These studies have prompted researchers to attempt to explain the inconsistencies. Shute (2008) noted in her review of the literature on formative feedback that "despite the plethora of research on the topic, the specific mechanisms relating feedback to learning are still mostly murky, with very few (if any) general conclusions" (p. 156).

Panadero and Lipnevich (2021) attribute this murkiness to the tendency of scholarship to focus on the role of the teacher, the process of feedback delivery, and the type of feedback message, rather than on the uptake of feedback. As a remedy, they conceptualize feedback processing as a mediator between the feedback provided and its cognitive, motivational, and metacognitive effects, and propose a model that will be included in the review section of this paper. Similarly, Wisniewski and colleagues (2020) suggest that to better understand the effects of feedback on achievement, it is essential to differentiate between cognitive, motor, motivational, and behavioral outcomes and the types and amount of feedback information conveyed. In our view, a limitation of the extant literature on feedback is that it tends to treat feedback as something given, rather than received (Hattie and Gan, 2011): "There is no point in sending [the learner] messages if they are treated as noise or redundancy, and not as intelligible or pertinent information likely to help him or her to understand, remember, assimilate knowledge or develop skills" (Perrenoud, 1998, p. 86). This crucial aspect of formative assessment that has been often discussed but too rarely studied is students' responses to feedback, or the internal mechanisms involved in the reception of feedback and their influences on learning and achievement (Butler and Winne, 1995; Kluger and DeNisi, 1996; Shute, 2008; Draper, 2009; Bennett, 2011; Dann, 2014; Panadero and Lipnevich, 2021). We must understand students' responses to feedback to explain why feedback works when it does and why it does not work when it does not (Leighton, 2019). This becomes especially important when students are acknowledged as active self- and co-regulators in the feedback process (Panadero et al., 2018; Allal, 2020; Andrade and Brookhart, 2020; Chen and Bonner, 2020; Winstone and Boud, 2020). Thus, students' responses to feedback is the focus of our paper; we call it the next black box. 


\section{STUDENTS' RESPONSES TO FEEDBACK}

The first author conducted a search of the post-1998 literature on feedback processing, perceptions, responses, reactions, and receptivity to feedback within a formative assessment context. This resulted in over 200 potential screened sources and 100 sources to be reviewed. Based on this body of literature, responses to feedback can be broadly defined as the internal cognitive and affective mechanisms and overt behavioral responses or actions taken in response to feedback (Lipnevich et al., 2016). Overt behavioral responses are observable actions such as making revisions, help-seeking, trying harder, finding other strategies or additional information, and even ignoring the feedback (Draper, 2009; Winstone et al., 2021). Qualitative studies have shown that various factors, including students' emotions and judgments about the feedback, might influence behavioral responses, as well as how well students understand the feedback (e.g., Lipnevich and Smith, 2009b; Wingate, 2010; Winstone et al., 2021).

Internal cognitive and affective mechanisms are not as well defined as observable behavioral responses. Empirically, researchers tended to focus on conceptions of, perceptions of, and emotions elicited by feedback as key internal processes. In the following sections, we review empirical studies and then introduce and support a new, student-centered model that details key states and processes.

\section{Empirical Findings on Students' Responses to Feedback: Conceptions, Perceptions, and Emotions}

Our review (see also Fisk, 2017) revealed that scholars used different terminology to represent perceptions, including beliefs, conceptions, voice, views, and perspectives. Empirical studies on students' perceptions of feedback include but are not limited to individuals' emotions, judgments, conceptions, and uses of feedback, suggesting that these processes are all relevant to responses to feedback and might be co-occurring. For example, Lipnevich and Smith (2009b) found that, when students were asked about their reactions to feedback, they expressed both emotional and judgmental reactions (e.g., "I was relieved when I went through the comments," "I panicked," "I was shocked," and "I completely freaked out"), as well as perceptions, or judgment-related reactions (e.g., "Praise without comments is not worth much") (pp. 354-359).

Similarly, Gamlem and Smith (2013) conducted 11 interviews with lower secondary students on their perceived utility of corrective feedback, and the results included both perceptions and emotions. Cognitively, students found it difficult to make meaning out of vague feedback that did not elaborate on how they could improve (e.g., "write more, work harder or give a richer description when they find they have told everything they know" [p. 159]). Emotionally, these perceptions left students feeling frustrated and attacked instead of motivated. While conceptions, perceptions, and emotions might often co-exist, they are distinct constructs that we will parse in this paper to better identify and operationalize them as distinct internal mechanisms of feedback processing.

\section{Conceptions of Feedback}

According to McMillan (2016), conceptions of feedback are overall beliefs, values, or attitudes about feedback that individuals bring to any assessment event. For example, "I enjoy getting feedback" and "feedback makes me try harder" are items from the 32-item Students Conception of Feedback Inventory (SCoF-III), a survey that measures students' beliefs about the nature and purpose of feedback (Brown et al., 2016; Irving et al., 2007; Irving et al., 2008). This survey does not need to be administered in any specific tasks or feedback, assuming that conceptions are feedback- and task-general.

While conceptions of feedback are partially task general, they are also influenced by the assessment culture where learning happens. For example, students accustomed to receiving feedback with grades and without opportunities to revise tended to view receiving feedback as useless (Havnes et al., 2012). In contrast, high school students who have been exposed to student-centered assessment found value in using feedback (Harris et al., 2014). Correlational studies have provided support for the relationships that conceptions have with other motivational variables, including self-efficacy (Brown et al., 2016; Fatima et al., 2021) and goal orientation (Rakoczy et al., 2013), self-regulated learning (SRL) behaviors (Brown et al., 2016), satisfaction with feedback (Robinson et al., 2013), and academic performance (Brown et al., 2016).

\section{Perceptions of Feedback}

In comparison, we can consider perceptions of feedback as reflective judgments made during or after an assessment event about task-specific feedback that students have received. These judgments are made in terms of various feedback characteristics, including accuracy, usefulness, timeliness, and other judgmental values (Jonsson and Panadero, 2018; Van der Kleij and Lipnevich, 2021). As an illustrative example, Lipnevich and Smith (2009b) conducted a qualitative study with six focus groups comprising university students to examine students' perceptions of various feedback messages they received during specific feedback instances. When students were asked, "How did you react to the feedback?" they responded with statements like "the comments were really helpful," which were statements of judgments about the feedback they received.

\section{Emotions Elicited by Feedback}

Emotions elicited by feedback are a multi-dimensional affective process that can surface immediately or with a delay and vary across assessment events. For instance, Niven and Meyer (2007) reported on emotions elicited by feedback for 12 first-year undergraduate students. When asked, "What did you feel about your work being covered with the tutor's writing in green/pink ink?" students responded, "I was angry I couldn't take it," and "...very uncomfortable ... at school I always had perfect feedback. I wasn't offended, but I was shocked” (p.17).

Emotions can be characterized in terms of valence (negative or positive), activation (activate or deactivate motivation), and object-focus (activity or outcome; Pekrun, 2006; Pekrun et al., 2011; Peterson et al., 2015; Vogl and Pekrun, 2016). Anger is a negative, activating outcome emotion that triggers the intrinsic 
motivation to act on the outcome (Pekrun et al., 2007). Other academically relevant emotions include joy, hope, relief, pride, gratitude, enjoyment, hopelessness, anxiety, sadness, shame, frustration, and boredom (Pekrun, 2006). Illies et al. (2010) measured students' emotions elicited by their performance on an exam (relative to their goal) with a list of emotions similar to those of Pekrun (2006): excited, delighted, happy, glad, satisfied, proud, self-assured, angry, frustrated, guilty, ashamed, sad, disappointed, depressed, worried, fearful, and uncomfortable. These emotions were examined in terms of positive and negative valence. The results revealed that these emotional reactions and self-efficacy mediated the relationship between feedback and subsequent goals.

\section{Motivational Determinants of Responses to Feedback}

Research on responses to feedback suggests that additional internal factors might play a role, including self-efficacy, which refers to students' beliefs about their capabilities to achieve a specific goal or task (Bandura, 1986); goal orientation, which refers to students' purpose for engaging in a task or behavior (Dweck and Leggett, 1988; Elliot, 2005; Mega et al., 2014); mindset, which are one's beliefs about the malleability of intelligence (Dweck et al., 1995), and task motivation, which includes the extent to which one enjoys, is interested, finds relevance and/or importance in the topic or task at hand (Horvath et al., 2006).

In terms of self-efficacy, much is known about the effects of feedback on self-efficacy (e.g., Chan and Lam, 2010; Hier and Mahony, 2018) but far less about the relationships between selfefficacy and students' responses to feedback. An exception is a study by Wingate (2010), which suggests that critical feedback tended to be a motivator for improving writing for undergraduate students with higher levels of self-efficacy than students with lower levels of self-efficacy, for whom feedback was discouraging and promoted negative emotions. Also of note is a study by Illies and colleagues (2010), which revealed negative relationships between 493 undergraduate students' exam self-efficacy and negative emotions elicited by performance-goal discrepancy feedback. Their findings suggest that emotions play a moderating role between feedback and self-efficacy.

In terms of goal orientation, students who are mastery-goal oriented tend to strive to develop competence. In contrast, performance-approach students strive for a positive outcome and so approach tasks to demonstrate competence. Performance-avoidant students are often demotivated by the chance of a negative result and do not perform a task to avoid the anticipated outcome (Elliot, 2005). Research suggests a mediating role for feedback in the relationship between goal orientation and performance. For example, an initially positive relationship between performance-approach goal orientation and performance decreased when undergraduate students received performance feedback; there was no change in relationships between mastery-goal orientation and performance-avoidant orientation and performance (VandeWalle et al., 2001).

Mindset is also associated with how students respond to feedback. For example, Forsythe and Johnson (2017) reported that undergraduate students with fixed mindsets, compared to those with growth mindsets, tended to score lower on positive adaptive factors (i.e., self-observation, self-assertion, anticipation, sublimation, and humor) and higher on negative affect regulating factors (i.e., intellectualization, dissociation, and isolation) and defensive behaviors (i.e., complaining, rejecting, splitting, projecting).

Studies on task interest have shown that it plays a significant role in students' emotions, goal-setting (Horvath et al., 2006), academic achievement, and behaviors (Harackiewicz et al., 2000; Harackiewicz and Hulleman, 2010; Boekaerts, 2011). There is also evidence supporting the role of task interest in how students respond to feedback. Katz et al. (2006) conducted an experimental study with 91 seventh-grade children in Israel. Students were randomly assigned to one of two groups: positive or no feedback groups. All students completed a selfreport questionnaire on interest in logic questions, puzzles, and thinking games before and after the feedback intervention. For students with moderate interest, a shift from presence to absence of positive feedback increased intrinsic motivation in females but decreased in males. The opposite pattern was found for students with low interest: Intrinsic motivation increased in males but decreased in females from receiving to not receiving positive feedback. For the students with high interest, interest was related to intrinsic motivation for both genders, with a slight decrease from the presence to the absence of positive feedback.

\section{Summary}

Our review of empirical studies of students' responses to feedback shows that the construct comprises conceptions, perceptions, emotion, and motivational states and traits. We concur with the conclusion made by Van der Kleij and Lipnevich (2021) in their critical scoping review of students' perceptions of feedback: research on this topic involves "a wide range of examined variables" (p. 367) and lacks a common theoretical framework.

\section{Models of Feedback and Responses to It}

We aim to develop a theoretical framework of students' responses to feedback that includes variables and processes with rigorous theoretical and empirical support. To do this, we review 14 of the most relevant and representative models and theories to identify key factors and variables. We summarize these models in Table 1 by model type, theories, focus, and the factors and processes they highlight.

In general, the models vary in type and include cycles, typologies, frameworks, theoretical arguments, processes, and taxonomies; they are grounded in formative assessment and self-regulated learning theories. The models are comprehensive, comprising contextual, external, internal, and personal factors. They also illustrate the hypothesized processes and interactions between and among identified factors. Taken together, the models posit that responses to feedback include initial states, which are factors and processes internal to the learner, such as task motivation, self-motivational beliefs, conceptions or beliefs about assessment and feedback, and prior knowledge; internal responses to feedback, which include regulatory learning processes, interpretations and perceptions of, and attributions made regarding the feedback, emotions elicited 
TABLE 1 | Summary of fourteen most relevant models related to responses to feedback.

\begin{tabular}{|c|c|c|}
\hline Source & Model type & Informed by \\
\hline $\begin{array}{l}\text { *Bangert-Drowns et al. } \\
\text { (1991) }\end{array}$ & $\begin{array}{l}\text { Cyclical five- } \\
\text { stage model }\end{array}$ & $\begin{array}{l}\text { Kulhavy (1977), Schimmel } \\
\text { (1983), Kulik and Kulik (1988); } \\
\text { meta-analysis of } 40 \text { articles on } \\
\text { feedback effects on error } \\
\text { correction }\end{array}$ \\
\hline $\begin{array}{l}\text { *Butler and Winne } \\
\text { (1995) }\end{array}$ & $\begin{array}{l}\text { Cyclical with } \\
\text { internal and } \\
\text { external } \\
\text { processes }\end{array}$ & $\begin{array}{l}\text { Theories of self-regulated } \\
\text { learning and motivation, e.g., } \\
\text { Bandura (1986), Carver and } \\
\text { Scheier (1990), Corno (1993), } \\
\text { Kuhl and Goschke (1994), } \\
\text { Mithaug (1993), Paris and } \\
\text { Byrnes (1989), Zimmerman } \\
\text { (1989) }\end{array}$ \\
\hline
\end{tabular}

\section{Focus of mode}

Learner's state in receiving mediated intentional feedback for retrieval accuracy

Feedback's roles in the dynamic cognitive and motivational processes that unfold during $S R L$ through monitoring

\section{Factors and processes included}

Initial states: interest, goal orientation, self-efficacy, prior knowledge

Cognitive system: search and retrieval strategies; evaluation of answers and feedback; decision-making on next steps; task expectations

Cognitive system: learner's motivational beliefs, knowledge, and skills; SRL processes (goal-setting, strategies selections, progress monitoring, products External: task; external feedback; performance

\begin{tabular}{ll}
\hline Tunstall and Gipps & Typology \\
(1996) & Lesson observations in \\
& London with eight teachers \\
& and 49 students in six \\
& elementary level classes
\end{tabular}

Types and characteristics of feedback teachers give to children and how children understand the feedback

\section{Allal and Lopez (2005) Framework}

Regulation of learning literature
Formative assessment as feedback + adaptation
Feedback types for assessment purposes vary on a continuum from evaluative to descriptive, and from positive to negative:

1) Rewarding-punishing to promote classroom management

2) Approving-disapproving to promote performance 3) Specifying attainment-specifying improvement to promote mastery

4) Constructing achievement-constructing the way forward to promote learning

\section{Externally-driven regulation:}

1) Interactive regulation: feedback during learning activity to promote continuous adaptations of learning in-situ 2) Retroactive regulation: feedback after assessment information has been collected for remediation purposes 3) Proactive regulation: feedback before the start of a learning event, to prepare, plan and design the most appropriate learning activities

\begin{tabular}{|c|c|c|c|}
\hline $\begin{array}{l}\text { Hattie and Timperley } \\
\text { (2007) }\end{array}$ & Framework & $\begin{array}{l}\text { Analyses of meta-analyses, } \\
\text { including Hattie's (1999) } \\
\text { synthesis of over } 500 \text { meta- } \\
\text { analyses; } 12 \text { meta-analyses } \\
\text { assessing influences of } \\
\text { feedback. Sadler (1989) }\end{array}$ & $\begin{array}{l}\text { Feedback used to enhance } \\
\text { learning by reducing } \\
\text { discrepancies between } \\
\text { current understandings, } \\
\text { performance, and goals }\end{array}$ \\
\hline
\end{tabular}

Internal or external: metacognitive questions (Where am I going? How am I going? Where to next? External: feedback (task, process, self-regulation, self) 1) Task level to inform students of how well the task is understood

2) Process level lets students know of the processing needed to understand or perform the task 3) Self-regulation level to bring awareness to students of self-regulated learning strategies they are using or should use

4) Self-level feedback to evaluate the student as a person

\section{Attributions students make about the ambiguous} feedback: 1) knowledge or skills used; 2) effort in terms of time, physical and mental exertion; 3) learning strategies used to understand expectations of the task; 4) innate ability, trait, or aptitude; 5) external, uncontrollable, or unstable reasons; 6) judging feedback as inaccurate or irrelevant

Decisions regarding self-management actions: 1) practice or improve knowledge and skills; 2) alter time and effort allocated to the task; 3) Find and try new study methods; find more or better information to better understand task expectation; 4) change courses; 5) persist; 6) get a second opinion; 7) doing nothing

Internal: learner's motivational beliefs, knowledge, and skills; SRL processes (goal-setting, planning, strategies selections, progress monitoring, adjustments/revisions) External: task; teacher's interpretation of student progress; instructional adjustments; teacher expectations 
TABLE 1 | (Continued) Summary of fourteen most relevant models related to responses to feedback.

\begin{tabular}{|c|c|c|c|}
\hline Source & Model type & Informed by & Focus of model \\
\hline $\begin{array}{l}\text { Gamlem and Smith } \\
\text { (2013) }\end{array}$ & Typology & $\begin{array}{l}\text { Tunstall and Gipps (1996); } \\
\text { Interviews }(n=11) \text { and lesson } \\
\text { observations with } 150 \text { lower } \\
\text { secondary school students in } 6 \\
\text { classes to understand } \\
\text { students' perceptions of useful } \\
\text { classroom feedback }\end{array}$ & $\begin{array}{l}\text { Student's perceptions of } \\
\text { feedback by feedback types }\end{array}$ \\
\hline
\end{tabular}

\section{Factors and processes included}

Feedback types: 1) rewarding - grade giving - punishing; 2) approving-controlling-disapproving; 3) specifying attainment-reporting-specifying improvement; 4) constructing achievement-dialogic feedback interaction-constructing the way forward Student perceptions of each feedback type: 1) effort and engagement are used to determine grades; grades are values placed on student performance, and come without comments 2) acceptance (e.g., checkmark, smile) or rejection (e.g., cross-out, frown) from the teacher; outcome feedback; evaluative; (de)motivating; 3) can come from a teacher, peers, or self; requires active participation (listening, empathy, self-assessment); assessment based on criteria; opportunities for improvement; 4) dialogic feedback interaction; useful feedback that happens in-situ, with immediate access to thoughts, actions, and work; the rarest type of feedback, but enhances learning when used; can come from teachers, peers, or self; promotes self-regulation

*Narciss (2013)

Cyclical, with internal and external processes
Systems theory; research on interactive instruction, elaborated feedback, task and error analyses, tutoring techniques
Formative tutoring feedback as a multidimensional instructional activity to improve regulation of learning, competencies, and mastery

Instructional context: domain, topic, curriculum; goals, methods, materials, resources, and tools; learning task, standards and competencies

External feedback: messages (evaluative and tutoring information and suggested next steps); functions (cognitive, metacognitive, motivational) Personal factors: prior knowledge; understanding of standards and competencies; self-assessment skills; information processing strategies and skills; will and skills to overcome obstacles

Internal: cognitive, metacognitive, motivational processes; comparing current state of competency to external standards and feedback; identifying sources of discrepancies; making decisions on next steps (e.g., error correction strategies, revision activities)

Behavioral response: implementing next actionable steps

Contextual factors: task, error climate, situation Personal traits: learner's prior learning experiences and outcomes, knowledge and abilities; motivational traits and beliefs

Regulation processes: appraisals; emotions (e.g., $\overline{\text { surprised, confused); }}$ cognitive strategies, metacognitive activities

*Lipnevich et al. (2016) and Van der Kleij and Lipnevich (2021)

Process model with inputs and outputs

Literature on feedback

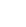
Learner's affective and
cognitive responses to
feedback

*Winstone et al. (2017) Taxonomy
Systematic literature review of learner's proactive engagement with feedback processes
Supporting learner's agentic engagement with feedback, or what Winstone and colleagues termed, "proactive recipience of feedback."
Personal traits: learner's subjective beliefs, abilities, receptivity of feedback

External: feedback and its characteristics; learner's behavioral response; context where feedback was received Internal: affective response (discrete emotions), and cognitive response (comprehension, receptivity) Contextual factors: assessment and curriculum design, learning environment, timing of feedback, institutional policies

Feedback interventions: aimed at 1) internalizing and applying standards, 2) sustainable monitoring, 3) feedback training, 4) approaches to feedback delivery External: feedback message and its characteristics; behavior of feedback giver; behavior of the learner Internal (to the giver of feedback): personal characteristics and beliefs (e.g., perceptions of feedback) Internal (to the learner): personal characteristics and beliefs (e.g., perceptions, knowledge, and abilities); SAGE process (self-appraisal, assessment literacy, goal-setting, self-regulation, engagement, motivation) The emphasis is on the interaction among these factors 
TABLE 1 | (Continued) Summary of fourteen most relevant models related to responses to feedback.

\begin{tabular}{|c|c|c|c|c|}
\hline Source & Model type & Informed by & Focus of model & Factors and processes included \\
\hline *Leighton (2019) & $\begin{array}{l}\text { Cyclical process, } \\
\text { with internal and } \\
\text { external } \\
\text { processes }\end{array}$ & $\begin{array}{l}\text { Pellegrino et al. (2016), } \\
\text { assessment literature, } \\
\text { intertwined with psychology } \\
\text { literature }\end{array}$ & $\begin{array}{l}\text { Instructional and psychological } \\
\text { relevance of formative } \\
\text { assessment }\end{array}$ & $\begin{array}{l}\text { External: objectives, task, and expected outcomes; } \\
\text { teacher feedback to students; students' behavioral } \\
\text { responses to feedbacks } \\
\text { Internal: teacher diagnosis of learning; students' } \\
\text { interpretation of feedback } \\
\text { The emphasis is on understanding the psychological } \\
\text { mechanisms involved within the formative assessment } \\
\text { process }\end{array}$ \\
\hline $\begin{array}{l}\text { *Panadero and } \\
\text { Lipnevich (2021) }\end{array}$ & Typology & $\begin{array}{l}\text { Review of fourteen models: } \\
\text { Ramaprasad (1983), Kulhavy } \\
\text { and Stock (1989), Sadler } \\
\text { (1989), Bangert-Drowns et al. } \\
\text { (1991), Butler and Winne } \\
\text { (1995), Kluger and DeNisi } \\
\text { (1996), Tunstall and Gipps } \\
\text { (1996), Mason and Bruning } \\
\text { (2001), Narciss (2013), Nicol } \\
\text { and McFarlane-Dick (2006), } \\
\text { Hattie and Timperley (2007), } \\
\text { Evans (2013), Lipnevich et al. } \\
\text { (2016), Carless and Boud } \\
\text { (2018) }\end{array}$ & $\begin{array}{l}\text { An integrative model of } \\
\text { feedback: Message, } \\
\text { Implementation, Student, } \\
\text { Context, and Agents (MISCA), } \\
\text { situating students in the center } \\
\text { of this model }\end{array}$ & $\begin{array}{l}\text { Contextual: climate at the educational system, } \\
\text { institutional, discipline, and classroom levels; pedagogical } \\
\text { approaches to feedback and the presentation of it (e.g., } \\
\text { timing, delivery mode); learning objectives; task and } \\
\text { expectations } \\
\text { Feedback: characteristics (e.g., message, purpose, } \\
\text { clarity and accessibility); sources (e.g., teachers, } \\
\text { students, technology, self) } \\
\text { Internal: Students' individual differences (e.g., cognitive } \\
\text { ability, prior knowledge, self-regulated learning skills, } \\
\text { personality traits); reception and agentic use of feedback } \\
\text { (e.g., decoding, analyzing, implementing the feedback); } \\
\text { cognitive, affective, motivational, and self-regulated } \\
\text { learning processes } \\
\text { This model also emphasizes the interaction among these } \\
\text { factors }\end{array}$ \\
\hline
\end{tabular}

The asterisk (*) denotes the models that focus on students' internal processing of feedback.

by the feedback, and decisions that are made about next steps; and overt, observable external responses to feedback, which include students' behavioral responses and performance. The models also acknowledge the importance of contextual, external factors, including the nature of the feedback, the task, and the culture of assessment and learning in which the feedback is given.

Acknowledging the many factors and processes involved in feedback and feedback processing has revealed its complexities but by being comprehensive, these models have also sacrificed depth for breadth. Ten of the 14 models (indicated by * in Table 1) focus on students' internal processing of feedback but sometimes do not describe it in sufficient detail (e.g., Panadero and Lipnevich, 2021). These 10 models have similarities and differences that, collectively, inform the design of a new, detailed model that is student-centered and identifies key states and processes experienced by the students. Combined with the empirical findings reviewed above, these models show that when students receive feedback as input, they decide on their next steps, which leads to behavioral outputs (Lipnevich et al., 2016). What happens in between is something of a black box, but here are some evidence-based speculations regarding what responses to feedback include:

1) Emotions that play a role in achievement behaviors (Lipnevich et al., 2016; Tulis et al., 2016; Vogl and Pekrun, 2016);

2) Judgments about and receptiveness to the feedback (Draper, 2009; Gamlem \& Smith, 2013; Lipnevich et al., 2016);

3) Interpretation about the feedback, including how one makes sense of it (Sadler, 1998; Andrade, 2013; Leighton, 2019);
4) Attributions that one makes about one's performance based on the feedback (Draper, 2009; Narciss, 2013; Winstone et al., 2017);

5) Decisions about the next steps to be made based on feedback (Bangert-Drowns et al., 1991; Draper, 2009; Narciss, 2013);

In addition, we hypothesize that personal and motivational factors play a mediating role between feedback and how one responds to it (Bangert-Drowns et al., 1991; Tulis et al., 2016). To represent these mechanisms and interactions more clearly, we have created the model in Figure 1, which is explained in the next section.

\section{MODEL OF THE INTERNAL MECHANISMS OF FEEDBACK PROCESSING}

The model of the internal mechanisms of feedback processing (Figure 1) depicts the hypothesized internal processes and acknowledges key external factors that come into play. At the macro-level of the model is the culture of assessment and learning, represented by the outer grey oblong area. Consistent with Lipnevich and colleagues' (2016) model, the internal mechanisms of feedback processing comprise inputs (external feedback [A]) and outputs (behavioral response [F] and academic achievement [G]). Solid black lines represent the empirically supported relationships discussed in the introduction (Hattie and Timperley, 2007; Shute, 2008; Lipnevich and Smith, 2009a; Hattie, 2009; Wiliam, 2010; 2013; Ruiz-Primo and Li, 2013; Van der Kleij et al., 2015; Wisniewski et al., 2020). 


\section{A-F}

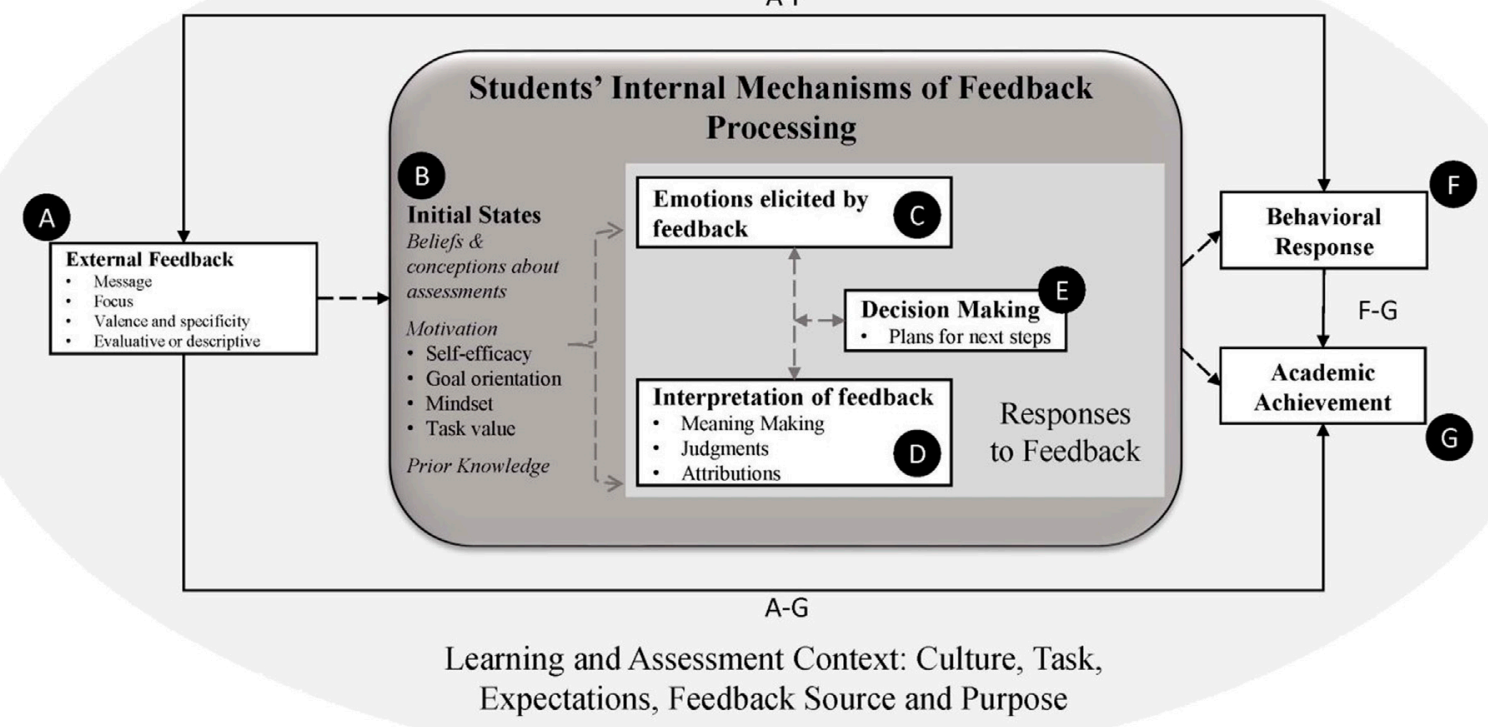

NOTE: solid lines = empirically supported relationships; dotted lines = proposed interplay of internal mechanisms in feedback processing

FIGURE 1 | Proposed mechanism involved in students' internal mechanisms of feedback processing.

The processes that are not yet well understood are the internal mechanisms between the inputs and outputs (B-E). Hypothesized processes include initial motivational states (B), which drive both affective and cognitive/metacognitive responses to feedback $(\mathrm{C}-\mathrm{E})$; that is, the internal processes in the rounded dark grey box are rooted in students' existing knowledge, beliefs, and motivational states, filtering information that learners receive and influencing the way they receive it.

While for the purposes of this study Figure 1 represents the processes sequentially, from inputs to outputs, we acknowledge that feedback processing is often cyclical and interactive: the outputs of a previous process inform the inputs of the next, and the processes interact with each other (Panadero and Lipnevich, 2021). Next, we discuss each element of the model and its support.

\section{Contextual, External Factors}

The assessment and learning context has been shown to influence how assessment information and feedback are used (e.g., Shepard, 2000; Hattie and Timperley, 2007; Havnes et al., 2012; Robinson et al., 2013; Lipnevich et al., 2016; Tulis et al., 2016; Winstone et al., 2017). When students are in a classroom that encourages a culture of critique, constructive feedback is welcomed and valued, and mistakes are treated as opportunities to learn (Hattie and Timperley, 2007; Andrade 2013). Tasks assigned to students are also influential (Butler and Winne, 1995; Hattie and Timperley, 2007; Andrade, 2013; Lipnevich et al., 2016; Pellegrino et al., 2016; Leighton, 2019). The Feedback Intervention Theory (FIT) highlights the importance of the task: what it is, how one completes it, and the processes that students engage in during the task (Kluger and DeNisi, 1996). The clarity of the task and the expectations are vital in activating the knowledge and skills needed for students to complete the task and understand the feedback received about performance (Leighton, 2019; Pellegrino et al., 2016; Wang et al., 2019).

Feedback is the external factor that activates internal processing (A in Figure 1). External feedback can come from many sources, including but not limited to teachers, peers, technology, and students themselves: Even self-generated feedback is guided by information from external sources (Allal, 2019; Andrade et al., 2021). Technology-generated feedback can be automated as in intelligent tutoring systems (e.g., Cutumisu et al., 2017; Perikos et al., 2017), or composed by a teacher, peer, or the students themselves and transmitted through a learning management system (e.g., Nguyen et al., 2017; Ramachandran et al., 2017; Donia et al., 2018; Winstone et al., 2021).

Regardless of the source and mode of feedback, feedback characteristics depend on the intended purpose and message (Panadero and Lipnevich, 2021). For example, a teacher who uses feedback to promote learning would likely use language that is more descriptive and less evaluative; a teacher who simply wants a student to know that the operation she used in a mathematics problem is wrong might choose to use more evaluative language (Tunstall and Gipps, 1996). In a computer-based learning environment where the intention is to offer other learning strategies for students to try, selfregulation feedback that answers "Where to next?" would be most appropriate (Hattie and Timperley, 2007). Feedback given 
to promote the internalization and application of standards would engage students with grading criteria that address the question, "Where am I going?" whether through self- or peer assessment or teacher-student dialogue and discussion (Winstone et al., 2017). Teachers might also return a markedup checklist or rubric to convey to students the expectations they have met and those they still need to work on, thus helping students to answer the question, "Where am I now?"

\section{The Internal Mechanisms \\ Motivational Determinants and Initial States}

Many motivational factors and initial states influence and are influenced by feedback and students' responses to it. We focus on six of the most well-studied motivational variables and initial states related to responses to feedback (B in Figure 1): 1) beliefs and conceptions about assessment (Robinson et al., 2013), 2) selfefficacy (Kluger and DeNisi, 1996; Shute, 2008; Chan and Lam, 2010; Wingate, 2010; Hier and Mahony, 2018), 3) academic goal orientation (VandeWalle et al., 2001; Rakoczy et al., 2013), 4) mindset (Cimpian et al., 2007; Forsythe and Johnson, 2017), 5) task value (Harackiewicz et al., 2000; Harackiewicz and Hulleman, 2010; Boekaerts, 2011), and prior knowledge (Fyfe and Rittle-Johnson, 2016; Fyfe and Rittle-Johnson, 2016).

Bangert-Drowns et al. (1991) appropriately called these factors "initial states" (p. 217) because they form the state that students are in at the time that they receive the feedback and influence how they receive and respond to it. They are usually represented as antecedents to responses to feedback, but they also end every feedback loop, perhaps altered by the previous learning experiences (Tulis et al., 2016). For example, domain knowledge, strategy knowledge, and motivational beliefs precede self-regulatory processes (Butler and Winne, 1995; Andrade, 2013); students' interest, goal orientation, selfefficacy, and prior knowledge initiate Bangert-Drowns and colleagues' (1991) cyclical five-stage model; and students' ability, prior success, general receptivity of feedback, and expectation for feedback precede students' cognitive and affective responses to feedback (Lipnevich et al., 2016).

\section{Responses to Feedback}

Once feedback filters through students' initial states, it enters the cognitive and affective processing phases: students' responses to feedback (C-E). When these processes are activated, students become proactive feedback recipients in a "state or activity of engaging actively with feedback processes" (Winstone et al., 2017, p. 17). Internal and regulatory processes involved in students' responses to feedback include emotions, interpretations, and decisions about the next steps. The model also posits an interplay between these factors, suggesting that emotions, interpretations, and decisions could change as students process the feedback. We explain each factor below.

\section{Emotions}

As discussed earlier in this paper, empirical investigations have elucidated emotions elicited by feedback (C; e.g., Gamlem and Smith, 2013; Lipnevich and Smith, 2009b; Niven and Meyer, 2007; Vogl and Pekrun, 2016). Kleij and Lipnevich's (2021) review of the literature found a relationship between emotions and perceptions of feedback, both negative and positive, and an association between negative emotions and vague or unclear feedback.

Consistent with these studies, emotions are represented in feedback models and responses to feedback as internal processes (e.g., Lipnevich et al., 2016; Tulis et al., 2016). Tulis and colleagues' model highlights two roles that emotion plays: First, it serves as a tool for monitoring the gaps in where students are in relation to their goals; second, it serves as a guide for their next steps. According to Pekrun's (2006) dimensions of academic emotions, they can motivate or demotivate students to take the next steps, whether the emotions are negative or positive.

\section{Interpretations}

Students' interpretation of feedback is well-represented in theory and models (Sadler, 1998; Hattie and Gan, 2011; Andrade, 2013; Dann, 2014) but less well supported by empirical studies, particularly in terms of the relationships between interpretations and motivational and contextual factors. Many models seem to assume that the feedback message is clear enough for all students to understand it as intended, thereby showing a clear path to the tactics and strategies they should use, the goals they should set, or adjustments they need to make to their learning. Unfortunately, not all feedback messages are received and understood as intended (Sadler, 1998; Higgins et al., 2001), especially when the feedback is vague, misaligned with expectations, or unclear (Draper, 2009; Leighton, 2019).

Leighton (2019) recently expanded on Pellegrino and colleagues' (2016) assessment model and argued that students' interpretation of feedback has vital implications for consequential validity because "it has a powerful role in determining student engagement with the [feedback] intervention and ultimately the efficacy of the feedback in learning performance" (p. 18). Questions such as, "Did the learner understand the feedback?" "Is the feedback worthy of follow-through from the student, and if not, why not?" are essential to ask during the formative assessment process, particularly after teachers have provided feedback based on their prognosis of student learning, and before students' implement the feedback, if they do at all. Leighton asserts that students' interpretations of feedback, or "generating meaning from an activity to inform action" (p. 2), must be understood, as well as the cognitive and emotional processes that are inevitably attached to them.

Therefore, drawing on existing models and empirical studies, interpretation of feedback is operationalized in our model as meaning making (Leighton, 2019), attributions based on feedback (Draper, 2009; Tulis et al., 2016; Winstone et al., 2017), and judgments or appraisals made about it (Draper, 2009; Gamlem and Smith, 2013; Lipnevich et al., 2016; Winstone et al., 2017).

\section{Decision-making}

Factor E in our model indicates that emotions and interpretations, taken together, help determine students' decisions about next steps to take with their learning after 
receiving feedback. When feedback from the teacher is clear, it can help students understand what they know (or do not know) and perhaps even how they know it (or do not know it). In turn, students might decide to engage with the feedback at a surface level, through reflection on the comments, or with an in-depth synthesis of the feedback to find common themes and methods to address them (Winstone et al., 2021).

Students make various causal inferences about why they received the feedback they did, each influencing the decisions about next steps. Some of those steps are adaptive, such as improving knowledge and skills, altering effort, and finding other methods to learn about the task. Others are maladaptive, including deciding to avoid processing the feedback (Winstone et al., 2021) or ignoring the feedback if it was judged as inaccurate or irrelevant (Draper, 2009).

\section{The Interplay between Interpretations, Emotions, and Decision-Making}

Interpretations about the feedback, emotions elicited by the feedback, and the decisions made about next steps are modeled as distinct processes in Figure 1, but the dotted bi-directional arrows between them represent research and theories that acknowledge that these processes work together and are sometimes inseparable (Lipnevich et al., 2016; Tulis et al., 2016; Winstone et al., 2017). For example, emotions can influence thinking differently depending on the timing and intensity of the thoughts (Petty and Brinol, 2014). That is, emotions could more easily change attitudes that are weak, whereas emotions would further strengthen or bias attitudes that are strong. Emotional processes also work together with attributional thinking to guide decisions to act in adaptive or maladaptive ways (Weiner et al., 1972; Weiner, 1986). Wolters et al. (2013) found that attributions contributed to the variance explained in 224 high school students' academic behavior and cognitive engagement above and beyond selfefficacy, achievement goals, and student status. Attributions were more closely linked to proximal goals (e.g., effort and strategy use for the targeted class) than distal goals (e.g., intention to pursue a similar course in the future).

When added to the mix of judgment, attribution, decisionmaking, and emotional processes, types of feedback are not trivial either. For example, norm-referenced feedback promotes maladaptive attributional thinking (e.g., attributing failure to lack of ability) that demotivates efforts on subsequent tasks (Kluger and DeNisi, 1996). The feedback that requires low-level thinking, such as corrections and exact edits marked on student essays by teachers, resulted in subsequent compliance by the students-that is, students made the changes without questioning them, even if it meant sacrificing the quality of work in other ways (Dohrer, 1991). Students judged the feedback as more valuable and desirable by students when it required them to think about their work (Gamlem and Smith, 2013). The model aims to extend this body of literature and examine the relationships between feedback, motivational states (i.e., self-motivational beliefs, task values), and responses to feedback (i.e., emotions elicited by feedback, interpretations of feedback, decision-making).

\section{DISCUSSION AND IMPLICATIONS}

From a learner's perspective, formative assessment is an inferential process in which external feedback is interpreted to inform decisions and behavioral responses (Bennett, 2011). Students do not always receive feedback in the way the teacher has intended (Higgins et al., 2001). To understand how students respond to feedback, one must not only be aware of the characteristics and purposes of the feedback that teachers provide but also the processes that happen internally as students receive and interpret the feedback. Students' cognitive and affective responses to feedback play an essential role in their engagement with it and the efficacy of the feedback in influencing student learning or performance (Leighton, 2019). A comprehensive and useful model of feedback must explain how it is received.

Empirical studies on responses to feedback have focused on students' conceptions of, perceptions of, and emotions elicited by feedback, as well as behavioral responses to it. This body of research also reveals the role that self-efficacy, goal orientation, mindset, and task motivation play in how students make decisions and respond behaviorally to feedback. Theoretical models echo the importance of these factors (i.e., emotions, perceptions, decision-making, motivation) and posit additional factors, including interpretations of feedback (i.e., meaning making, judgments, and attributions). The model proposed in this paper (Figure 1) operationalizes responses to feedback in measurable ways, so we can transition from postulating to measuring.

\section{Future Directions for Research}

This model of the mechanisms of feedback processing can shed light into the next black box by guiding empirical studies of these processes and their relationships with each other, thereby moving in the direction of treating feedback as something received. We conducted one such empirical study to validate a self-report measure of responses to feedback (Lui and Andrade, 2021). That study was conducted in a seventh grade English language arts class familiar with formative assessment methods and where a culture of critique had been established. The study provided initial empirical support for our model; additional research is needed to test our model in a variety of contexts, including those that emphasize summative evaluation and serve a variety of age ranges.

Given that feedback is discipline-specific (Andrade et al., 2019), research is also needed on how responses to feedback differ by discipline and grade level. For example, what are students' responses to feedback-emotions, judgments, meaning making, attributions, decision-making-in a college-level visual arts class that involves highly critical critiques by the instructor? How are these students' response processes related to their motivational and initial states (e.g., self-efficacy, mindset, goal orientation, task value, prior knowledge)? How do students' responses to feedback vary by source, i.e., teacher-, computer-, peer-, and self-generated feedback?

Our model focuses on six of the most well-studied motivational determinants and initial states related to responses to feedback (i.e., beliefs and conceptions about assessment, self-efficacy, academic goal orientation, mindset, task value, and prior knowledge). As initial states, these 
variables are treated as antecedents to students' responses to feedback; but they are malleable and can be influenced by feedback (VandeWalle et al., 2001; Cimpian et al., 2007; Chan and Lam, 2010; Hier and Mahony, 2018). Therefore, future research could examine if and how these motivational determinants and initial states change depending on how students respond to the feedback. Furthermore, there might be other motivational variables and initial states, beyond the six represented in the model, that play a vital role in how students respond to feedback. Therefore, questions such as "What other motivational beliefs and initial states influence and are influenced by feedback?" could be important to explore.

\section{CONCLUSION}

In this paper, we introduced the next black box of formative assessment and presented the model of the internal mechanisms of feedback processing, a theoretical framework of students' responses to feedback that includes variables and hypothesized processes with rigorous theoretical and empirical support. As findings from future research are shared, the hypothesized

\section{REFERENCES}

Allal, L. (2019). Assessment and the Co-regulation of Learning in the Classroom. Assess. Educ. Principles, Pol. Pract. 27 (4), 332-349. doi:10.1080/0969594X. 2019.1609411

Allal, L. (2020). Assessment and the Co-regulation of Learning in the Classroom. Assess. Educ. Principles, Pol. Pract. 27 (4), 332-349. doi:10.1080/0969594X. 2019.1609411

Allal, L., and Lopez, L. M.OECD (2005). "Formative Assessment of Learning: A Review of Publications in French," in Formative Assessment: Improving Learning in Secondary Classrooms (Paris: OECD), 241-264.

Andrade, H., Brookhart, S., and Yu, E. C. (2021). Classroom Assessment as Co-regulated Learning: A Systematic Review. Front. Educ. doi:10.3389/feduc.2021.751168

Andrade, H. (2016). Classroom Assessment and Learning: A Selective Review of Theory and Research [White Paper]. Washington, DC: National Academy of Sciences.

Andrade, H. (2013). "Classroom Assessment in the Context of Learning Theory and Research," in SAGE Handbook of Research on Classroom Assessment. Editor J. H. McMillan (New York: SAGE), 17-34.

Andrade, H. L., and Brookhart, S. M. (2020). Classroom Assessment as the Coregulation of Learning. Assess. Educ. Principles, Pol. Pract. 27 (4), 350-372. doi:10.1080/0969594X.2019.1571992

Bandura, A. (1986). Social Foundations of Thought and Action: A Social Cognitive Theory. Englewood Cliffs, NJ: Prentice-Hall.

Bangert-Drowns, R. L., Kulik, C.-L. C., Kulik, J. A., and Morgan, M. (1991). The Instructional Effect of Feedback in Test-like Events. Rev. Educ. Res. 61 (2), 213-238. doi:10.3102/00346543061002213

Bennett, R. E. (2011). Formative Assessment: A Critical Review. Assess. Educ. Principles, Pol. Pract. 18 (1), 5-25. doi:10.1080/0969594X.2010.513678

Black, P., and Wiliam, D. (1998). Assessment and Classroom Learning. Assess. Educ. Principles, Pol. Pract. 5 (1), 7-74. doi:10.1080/0969595980050102

Black, P., and Wiliam, D. (2009). Developing the Theory of Formative Assessment. Educ. Asse Eval. Acc. 21 (1), 5-31. doi:10.1007/s11092-008-9068-5

Boekaerts, M. (2011). "Emotions, Emotion Regulation, and Self-Regulation of Learning," in Handbook of Self-Regulation of Learning and Performance. Editors B. J. Zimmerman and D. H. Schunk (New York: Routledge), 408-425. processes in this model will be refined and strengthened, and additional factors will be added. Ultimately, we will increase our understanding of what happens in the minds and hearts of students as they process feedback and assessment information, enabling us to better predict and control the effects of feedback and formative assessment on student performance and achievement.

\section{DATA AVAILABILITY STATEMENT}

The original contributions presented in the study are included in the article/Supplementary Material, further inquiries can be directed to the corresponding author.

\section{AUTHOR CONTRIBUTIONS}

The manuscript is a part of AL's dissertation. HA, AL's dissertation chair, provided copious support and feedback on the ideas and writing. Both authors contributed equally to the manuscript revision and read and approved the submitted version.

Brown, G. T., Peterson, E. R., and Yao, E. S. (2016). Student Conceptions of Feedback: Impact on Self-Regulation, Self-Efficacy, and Academic Achievement. Br. J. Educ. Psychol. 86 (4), 606-629. doi:10.1111/bjep.12126

Butler, D. L., and Winne, P. H. (1995). Feedback and Self-Regulated Learning: A Theoretical Synthesis. Rev. Educ. Res. 65 (3), 245-281. doi:10.3102/ 00346543065003245

Butler, R. (1987). Task-Involving and Ego-Involving Properties of Evaluation: Effects of Different Feedback Conditions on Motivational Perceptions, Interest, and Performance. J. Educ. Psychol. 79 (4), 474.

Carless, D., and Boud, D. (2018). The Development of Student Feedback Literacy: Enabling Uptake of Feedback. Assess. Eval. Higher Educ. 43 (8), 1315-1325.

Carver, C. S., and Scheier, M. (1990). Principles of self-regulation: Action and emotion. New York: The Guilford Press.

Chan, J. C. Y., and Lam, S.-f. (2010). Effects of Different Evaluative Feedback on Students' Self-Efficacy in Learning. Instr. Sci. 38 (1), 37-58. doi:10.1007/s11251-008-9077-2

Chen, P. P., and Bonner, S. M. (2020). A Framework for Classroom Assessment, Learning, and Self-Regulation. Assess. Educ. Principles, Pol. Pract. 27 (4), 373-393. doi:10.1080/0969594X.2019.1619515

Cimpian, A., Arce, H. M., Markman, E. M., and Dweck, C. S. (2007). Subtle Linguistic Cues Affect Children's Motivation. Psychol. Sci. 18 (4), 314-316. doi:10.1111/j.1467-9280.2007.01896.x

Corno, L. (1993). The best-laid plans: Modern Conceptions of Volition and Educational Research. Educ. Res. 22 (2), 14-22.

Cutumisu, M., Blair, K. P., Chin, D. B., and Schwartz, D. L. (2017). Assessing whether Students Seek Constructive Criticism: The Design of an Automated Feedback System for a Graphic Design Task. Int. J. Artif. Intell. Educ. 27 (3), 419-447. doi:10.1007/s40593-016-0137-5

Dann, R. (2014). Assessmentaslearning: Blurring the Boundaries of Assessment and Learning for Theory, Policy and Practice. Assess. Educ. Principles, Pol. Pract. 21 (2), 149-166. doi:10.1080/0969594X.2014.898128

Dohrer, G. (1991). Do Teachers' Comments on Students' Papers Help. Coll. Teach. 39 (2), 48-54. doi:10.1080/87567555.1991.9925485

Donia, M. B. L., O’Neill, T. A., and Brutus, S. (2018). The Longitudinal Effects of Peer Feedback in the Development and Transfer of Student Teamwork Skills. Learn. Individual Differences 61, 87-98. doi:10.1016/j.lindif.2017.11.012

Draper, S. W. (2009). What Are Learners Actually Regulating when Given Feedback. Br. J. Educ. Technol. 40 (2), 306-315. doi:10.1111/j.1467-8535.2008.00930.x1 
Dweck, C. S., and Leggett, E. L. (1988). A Socialcognitive Approach to Motivation and Personality. Psychol. Rev. 95 (2), 256-273. doi:10.1037/0033-295x.95.2.256

Dweck, C. S., Chiu, C.-y., and Hong, Y.-y. (1995). Implicit Theories and Their Role in Judgments and Reactions: A Word from Two Perspectives. Psychol. Inq. 6 (4), 267-285. doi:10.1207/s15327965pli0604_1

Dweck, C. S. (1999/2000). Self-theories: Their Role in Motivation, Personality, and Development. Philadelphia, PA: Psychology Press.

Elliot, A. J. (2005). "A Conceptual History of the Achievement Goal Construct," in Handbook of Competence and Motivation. Editors A. J. Elliot and C. S. Dweck (New York: Guilford Press), 52-72.

Evans, C. (2013). Making Sense of Assessment Feedback in Higher Education. Rev. Educ. Res. 83 (1), 70-120.

Fatima, S., Ali, M., and Saad, M. I. (2021). The Effect of Students' Conceptions of Feedback on Academic Self-Efficacy and Self-Regulation: Evidence from Higher Education in Pakistan. Jarhe. doi:10.1108/JARHE-07-2020-0209

Filsecker, M., and Kerres, M. (2012). Repositioning Formative Assessment from an Educational Assessment Perspective: A Response to Dunn \& Mulvenon, 17. Amherst, MA: Practical Assessment, Research, and Evaluation. doi:10.7275/ xrkr-b675

Fisk, S. M. (2017). A Qualitative Inquiry of Students' and Teachers' Perceptions on Feedback in Three Queensland Secondary Schools. Brisbane: Publication No. 112506. Queensland University of Technology. doi:10.5204/thesis.eprints. 112506

Forsythe, A., and Johnson, S. (2017). Thanks, but No-Thanks for the Feedback. Assess. Eval. Higher Educ. 42 (6), 850-859. doi:10.1080/02602938.2016.1202190

Fyfe, E. R., and Rittle-Johnson, B. (2016). The Benefits of Computer-Generated Feedback for Mathematics Problem Solving. J. Exp. Child. Psychol. 147, 140-151. doi:10.1016/j.jecp.2016.03.009

Gamlem, S. M., and Smith, K. (2013). Student Perceptions of Classroom Feedback. Assess. Educ. Principles, Pol. Pract. 20 (2), 150-169. doi:10.1080/0969594X.2012.749212

Graham, S., Hebert, M., and Harris, K. R. (2015). Formative Assessment and Writing. Elem. Sch. J. 115 (4), 523-547. doi:10.1086/681947

Harackiewicz, J. M., Barron, K. E., Tauer, J. M., Carter, S. M., and Elliot, A. J. (2000). Short-term and Long-Term Consequences of Achievement Goals: Predicting Interest and Performance over Time. J. Educ. Psychol. 92 (2), 316-330. doi:10. 1O3W0022-O663.92.2.31610.1037/0022-0663.92.2.316

Harackiewicz, J. M., and Hulleman, C. S. (2010). The Importance of Interest: The Role of Achievement Goals and Task Values in Promoting the Development of Interest. Social Personal. Psychol. Compass 4 (1), 42-52. doi:10.1111/j.17519004.2009.00207.x

Harris, L. R., Brown, G. T. L., and Harnett, J. A. (2014). Understanding Classroom Feedback Practices: A Study of New Zealand Student Experiences, Perceptions, and Emotional Responses. Educ. Asse Eval. Acc. 26 (2), 107-133. doi:10.1007/s11092-0139187-5

Hattie, J. A. (1999). Influences on student learning (Inaugural professorial address, University of Auckland, New Zealand). Available at: http://www.arts .auckland. ac.nz/staff/index.cfm? $\mathrm{P}=8650$.

Hattie, J. A. C., and Gan, M. (2011). "Instruction Based on Feedback," in Handbook of Research on Learning and Instruction. Editors R. Mayer and P. Alexander (New York: Routledge), 249-271.

Hattie, J. A. C. (2009). Visible Learning: A Synthesis of 800+ Meta-Analyses on Achievement. New York: Routledge.

Hattie, J., and Timperley, H. (2007). The Power of Feedback. Rev. Educ. Res. 77 (1), 81-112. doi:10.3102/003465430298487

Havnes, A., Smith, K., Dysthe, O., and Ludvigsen, K. (2012). Formative Assessment and Feedback: Making Learning Visible. Stud. Educ. Eval. 38 (1), 21-27. doi:10. 1016/j.stueduc.2012.04.001

Hier, B. O., and Mahony, K. E. (2018). The Contribution of Mastery Experiences, Performance Feedback, and Task Effort to Elementary-Aged Students' SelfEfficacy in Writing. Sch. Psychol. Q. 33, 408-418. doi:10.1037/spq0000226

Higgins, R., Hartley, P., and Skelton, A. (2001). Getting the Message across: The Problem of Communicating Assessment Feedback. Teach. Higher Educ. 6 (2), 269-274. doi:10.1080/13562510120045230

H. L. Andrade, R. E. Bennett, and G. J. Cizek (Editors) (2019). Handbook of Formative Assessment in the Disciplines (New York: Routledge). doi:10.4324/9781315166933

Horvath, M., Herleman, H. A., and Lee McKie, R. (2006). Goal Orientation, Task Difficulty, and Task Interest: A Multilevel Analysis. Motiv. Emot. 30, 169-176. doi:10.1007/s11031-006-9029-6
Illies, R., Judge, T. A., and Wagner, D. T. (2010). The Influence of Cognitive and Affectivereactions to Feedback on Subsequent Goals: Role of Behavioral Inhibition/ activation. Eur. Psychol. 15 (2), 121-131. doi:10.1027/1016-9040/a000001

Irving, S. E., Peterson, E. R., and Brown, G. T. L. (2008). Feedback And Academic Achievement: The Relationship between Students' Conceptions of Feedback and Achievement. [Paper presentation]. Liverpool, UK: The 6th Biennial Conference of the International Test Commission.

Irving, S. E., Peterson, E. R., and Brown, G. T. L. (2007). Student Conceptions of Feedback: A Study of New Zealand Secondary Students. [Paper presentation]. Budapest, Hungary: Biennial Conference of the European Association for Research in Learning and Instruction.

Jonsson, A., and Panadero, E. (2018). "Facilitating Students' Active Engagement with Feedback," in The Cambridge Handbook of Instructional Feedback. Editors A. A. Lipnevich and J. K. Smith (Cambridge University Press), 531-554.

Katz, I., Assor, A., Kanat-Maymon, Y., and Bereby-Meyer, Y. (2006). Interest as a Motivational Resource: Feedback and Gender Matter, but Interest Makes the Difference. Soc. Psychol. Educ. 9, 27-42. doi:10.1007/s11218-005-2863-7

Kingston, N., and Nash, B. (2011). Formative Assessment: A Meta-Analysis and a Call for Research. Educ. Meas. Issues Pract. 30 (4), 28-37. doi:10.1111/j.17453992.2011.00220.x

Kluger, A. N., and DeNisi, A. (1996). The Effects of Feedback Interventions on Performance: A Historical Review, a Meta-Analysis, and a Preliminary Feedback Intervention Theory. Psychol. Bull. 119 (2), 254-284. doi:10.1037/ 0033-2909.119.2.254

Kuhl, J., and Goschke, T. (1994). A theory of action control: Mental subsystems, modes of control, and volitional conflict-resolution strategies. Volition Personality: Action vs. State Orientation 5, 93-124.

Kulhavy, R. W. (1977). Feedback in Written Instruction. Rev. Educ. Res. 47 (2), 211-232. doi:10.3102/00346543047002211

Kulhavy, R. W., and Stock, W. A. (1989). Feedback in Written Instruction: The Place of Response Certitude. Educ. Psychol. Rev. 1 (4), 279-308.

Kulik, J. A., and Kulik, C. L. C. (1988). Timing of Feedback and Verbal Learning. Rev. Educ. Res. 58 (1), 79-97.

Leighton, J. P. (2019). Students' Interpretation of Formative Assessment Feedback: Three Claims for Why We Know So Little about Something So Important. J. Educ. Meas. 56 (4), 793-814. doi:10.1111/jedm.12237

Lipnevich, A. A., and Smith, J. K. (2009a). Effects of Differential Feedback on Students' Examination Performance. J. Exp. Psychol. Appl. 15 (4), 319-333. doi:10.1037/a0017841

Lipnevich, A. A., Berg, D. A. G., and Smith, J. K. (2016). “Toward a Model of Student Response to Feedback," in The Handbook of Human and Social Conditions in Assessment. Editors G. T. L. Brown and L. R. Harris (New York: Routledge), 169-185.

Lipnevich, A. A., and Smith, J. K. (2009b). "I Really Need Feedback to Learn:" Students' Perspectives on the Effectiveness of the Differential Feedback Messages. Educ. Asse Eval. Acc. 21 (4), 347-367. doi:10.1007/s11092-009-9082-2

Lui, A. M., and Andrade, H. L. (2021). Inside the Next Black Box: Examining Students' Responses to Teacher Feedback in a Formative Assessment Context. [Manuscript submitted for publication]. Department of Educational and Counseling Psychology, University at Albany - SUNY.

Mason, B. J., and Bruning, R. H. (2001). Providing Feedback in Computer-Based Instruction: What the Research Tells us. CLASS Research Report No. 9. Center for Instructional Innovation, University of Nebraska-Lincoln.

McMillan, J. H. (2016). "Section Discussion: Student Perceptions of Assessment," in Handbook of Social and Human Conditions in Assessment. Editors G. T. L. Brown and L. R. Harris (New York: Routledge), 221-244.

McMillan, J. H., Venable, J. C., and Varier, D. (2013). Studies of the Effect of Formative Assessment on Student Achievement: So Much More Is Needed. Pract. Assess. Res. Eval. 18. doi:10.7275/tmwm-7792

Mega, C., Ronconi, L., and De Beni, R. (2014). What Makes a Good Student? How Emotions, Self-Regulated Learning, and Motivation Contribute to Academic Achievement. J. Educ. Psychol. 106 (1), 121-131. doi:10.1037/a0033546

Mithaug, D. E. (1993). Self-regulation theory: How Optimal Adjustment Maximizes Gain. Praeger Publishers/Greenwood Publishing Group.

Narciss, S. (2013). Designing and evaluating tutoring feedback strategies for digital learning. Digital Educ. Rev. 23, 7-26.

Nguyen, H., Xiong, W., and Litman, D. (2017). Iterative Design and Classroom Evaluation of Automated Formative Feedback for Improving Peer Feedback 
Localization. Int. J. Artif. Intell. Educ. 27 (3), 582-622. doi:10.1007/s40593-0160136-6

Nicol, D. J., and Macfarlane-Dick, D. (2006). Formative Assessment and Self-regulated Learning: a Model and Seven Principles of Good Feedback Practice. Stud. higher Educ. 31 (2), 199-218. doi:10.1080/03075070600572090

Niven, P., and Meyer, B. (2007). Understanding the Impact that Principled Formative Feedback Has on First Year Students Writing: Is it Useable or Not? an Action Research Project. Int. J. Learn. 14 (8), 13-22.

Panadero, E., Andrade, H., and Brookhart, S. (2018). Fusing Self-Regulated Learning and Formative Assessment: A Roadmap of where We Are, How We Got Here, and where We Are Going. Aust. Educ. Res. 45 (1), 13-31. doi:10. 1007/s13384-018-0258-y

Panadero, E., and Lipnevich, A. A. (2022). A Review of Feedback Models and Typologies: Towards an Integrative Model of Feedback Elements. Educ. Res. Rev. 35, 100416. doi:10.1016/j.edurev.2021.100416

Paris, S. G., and Byrnes, J. P. (1989). "The Constructivist Approach to Selfregulation and Learning in the Classroom," in Self-regulated Learning and Academic Achievement (New York: Springer), 169-200.

Pekrun, R., Frenzel, A. C., Goetz, T., and Perry, R. P. (2007). "The Control-Value Theory of Achievement Emotions," in Educational Psychology Series. Emotion in Education. Editors P. A. Schutz and R. Pekrun (Cambridge, MA: Elsevier Academic Press), 13-36. doi:10.1016/B978-012372545-5/50003-410.1016/b978-012372545-5/ 50003-4

Pekrun, R., Goetz, T., Frenzel, A. C., Barchfeld, P., and Perry, R. P. (2011). Measuring Emotions in Students' Learning and Performance: The Achievement Emotions Questionnaire (AEQ). Contemp. Educ. Psychol. 36 (1), 36-48. doi:10.1016/j.cedpsych.2010.10.002

Pekrun, R. (2006). The Control-Value Theory of Achievement Emotions: Assumptions, Corollaries, and Implications for Educational Research and Practice. Educ. Psychol. Rev. 18 (4), 315-341. doi:10.1007/s10648-006-9029-9

Pellegrino, J. W., DiBello, L. V., and Goldman, S. R. (2016). A Framework for Conceptualizing and Evaluating the Validity of Instructionally Relevant Assessments. Educ. Psychol. 51 (1), 59-81. doi:10.1080/00461520.2016.1145550

Perikos, I., Grivokostopoulou, F., and Hatzilygeroudis, I. (2017). Assistance and Feedback Mechanism in an Intelligent Tutoring System for Teaching Conversion of Natural Language into Logic. Int. J. Artif. Intell. Educ. 27 (3), 475-514. doi:10.1007/s40593-017-0139-y

Perrenoud, P. (1998). From Formative Evaluation to a Controlled Regulation of Learning Processes. Towards a Wider Conceptual Field. Assess. Educ. Principles, Pol. Pract. 5 (1), 85-102. doi:10.1080/0969595980050105

Peterson, E. R., Brown, G. T. L., and Jun, M. C. (2015). Achievement Emotions in Higher Education: A Diary Study Exploring Emotions across an Assessment Event. Contemp. Educ. Psychol. 42, 82-96. doi:10.1016/j.cedpsych.2015.05.002

Petty, R. E., and Briñol, P. (2014). Emotion and Persuasion: Cognitive and MetaCognitive Processes Impact Attitudes. Cogn. Emot. 29 (1), 1-26. doi:10.1080/ 02699931.2014.967183

Rakoczy, K., Harks, B., Klieme, E., Blum, W., and Hochweber, J. (2013). Written Feedback in Mathematics: Mediated by Students' Perception, Moderated by Goal Orientation. Learn. Instruction 27, 63-73. doi:10. 1016/j.learninstruc.2013.03.002

Ramachandran, L., Gehringer, E. F., and Yadav, R. K. (2017). Automated Assessment of the Quality of Peer Reviews Using Natural Language Processing Techniques. Int. J. Artif. Intell. Educ. 27 (3), 534-581. doi:10.1007/s40593-016-0132-x

Ramaprasad, A. (1983). On the Definition of Feedback. Syst. Res. 28 (1), 4-13. doi:10.1002/bs.3830280103

Robinson, S., Pope, D., and Holyoak, L. (2013). Can We Meet Their Expectations? Experiences and Perceptions of Feedback in First Year Undergraduate Students. Assess. Eval. Higher Educ. 38 (3), 260-272. doi:10.1080/02602938.2011.629291

Ruiz-Primo, M. A., and Li, M. (2013). "Examining Formative Feedback in the Classroom Context: New Research Perspectives," in SAGE Handbook of Research on Classroom Assessment. Editor J. H. McMillan (Thousand Oaks, CA: SAGE), 215-232.

Sadler, D. R. (1989). Formative Assessment and the Design of Instructional Systems. Instr. Sci. 18 (2), 119-144. doi:10.1007/BF00117714

Sadler, D. R. (1998). Formative Assessment: Revisiting the Territory. Assess. Educ. Principles, Pol. Pract. 5 (1), 77-84. doi:10.1080/0969595980050104
Schimmel, B. J. (1983). A Meta-Analysis of Feedback to Learners in Computerized and Programmed Instruction.

Shepard, L. A. (2000). The Role of Assessment in a Learning Culture. Educ. Res. 29 (7), 4-14. doi:10.3102/0013189X029007004

Shute, V. J. (2008). Focus on Formative Feedback. Rev. Educ. Res. 78 (1), 153-189. doi:10.3102/0034654307313795

Stiggins, R. (2005). From Formative Assessment to Assessment for Learning: A Path to Success in Standards-Based Schools. Phi Delta Kappan 87 (4), 324-328. doi:10.1177/003172170508700414

Tulis, M., Steuer, G., and Dresel, M. (2016). Learning from Errors: A Model of Individual Processes. Flr 4 (2), 12-26. doi:10.14786/flr.v4i2.168

Tunstall, P., and Gsipps, C. (1996). Teacher Feedback to Young Children in Formative Assessment: A Typology. Br. Educ. Res. J. 22 (4), 389-404. doi:10.1080/ 0141192960220402

Van der Kleij, F. M., Feskens, R. C. W., and Eggen, T. J. H. M. (2015). Effects of Feedback in a Computer-Based Learning Environment on Students' Learning Outcomes. Rev. Educ. Res. 85 (4), 475-511. doi:10.3102/ 0034654314564881

Van der Kleij, F. M., and Lipnevich, A. A. (2021). Student Perceptions of Assessment Feedback: A Critical Scoping Review and Call for Research. Educ. Asse Eval. Acc. 33, 345-373. doi:10.1007/s11092-020-09331-x

VandeWalle, D., Cron, W. L., and Slocum, J. W., Jr (2001). The Role of Goal Orientation Following Performance Feedback. J. Appl. Psychol. 86 (4), 629-640. doi:10.1037/0021-9010.86.4.629

Vogl, E., and Pekrun, R. (2016). "Emotions that Matter to Achievement: Student Feelings about Assessment," in Handbook of Social and Human Conditions in Assessment. Editors G. T. L. Brown and L. R. Harris (New York: Routledge), 1-35.

Wang, Z., Gong, S. Y., Xu, S., and Hu, X. E. (2019). Elaborated feedback and learning: Examining cognitive and motivational influences. Comput. Educ. 136, 130-140.

Weiner, B., Heckhausen, H., Meyer, W. U., and Cook, R. E. (1972). Causal Ascriptions and Achievement Behavior: A Conceptual Analysis of Effort and Reanalysis of Locus of Control. J. Pers Soc. Psychol. 21 (2), 239-248. doi:10.1037/h0032307

Weiner, B. (1986). "An Attributional Theory of Achievement Motivation and Emotion," in An Attributional Theory of Motivation and Emotion (Springer), 159-190. doi:10.1007/978-1-4612-4948-1_6

Wiliam*, D., Lee, C., Harrison, C., and Black, P. (2004). Teachers Developing Assessment for Learning: Impact on Student Achievement. Assess. Educ. Principles, Pol. Pract. 11 (1), 49-65. doi:10.1080/0969594042000208994

Wiliam, D. (2010). "An Integrative Summary of the Research Literature and Implications for a New Theory of Formative Assessment," in Handbook of Formative Assessment. Editors H. L. Andrade and G. J. Cizek (New York: Routledge), 18-40.

Wiliam, D. (2013). "Feedback and Instructional Correctives," in SAGE Handbook of Research on Classroom Assessment. Editor J. McMillan (Washington, DC: SAGE), 197.

Wiliam, D. (2011). What Is Assessment for Learning. Stud. Educ. Eval. 37 (1), 3-14. doi:10.1016/j.stueduc.2011.03.001

Wingate, U. (2010). The Impact of Formative Feedback on the Development of Academic Writing. Assess. Eval. Higher Educ. 35 (5), 519-533. doi:10.1080/ 02602930903512909

Winstone, N., Bourne, J., Medland, E., Niculescu, I., and Rees, R. (2021). "Check the Grade, Log Out": Students' Engagement with Feedback in Learning Management Systems. Assess. Eval. Higher Educ. 46 (4), 631-643. doi:10.1080/02602938.2020.1787331

Winstone, N. E., and Boud, D. (2020). The Need to Disentangle Assessment and Feedback in Higher Education. Stud. Higher Educ., 1-12. doi:10.1080/ 03075079.2020 .1779687

Winstone, N. E., Nash, R. A., Parker, M., and Rowntree, J. (2017). Supporting Learners' Agentic Engagement with Feedback: A Systematic Review and a Taxonomy of Recipience Processes. Educ. Psychol. 52 (1), 17-37. doi:10.1080/00461520.2016. 1207538

Wisniewski, B., Zierer, K., and Hattie, J. (2020). The Power of Feedback Revisited: A Meta-Analysis of Educational Feedback Research. Front. Psychol. 10 (3087), 3087. doi:10.3389/fpsyg.2019.03087

Wolters, C. A., Fan, W., and Daugherty, S. G. (2013). Examining Achievement Goals and Causal Attributions Together as Predictors of Academic Functioning. J. Exp. Educ. 81 (3), 295-321. doi:10.1080/00220973.2012.700498 
Zimmerman, B. J. (1989). A Social Cognitive View of Self-Regulated Academic Learning. J. Educ. Psychol. 81 (3), 329-339.

Conflict of Interest: The authors declare that the research was conducted in the absence of any commercial or financial relationships that could be construed as a potential conflict of interest.

Publisher's Note: All claims expressed in this article are solely those of the authors and do not necessarily represent those of their affiliated organizations, or those of the publisher, the editors and the reviewers. Any product that may be evaluated in this article, or claim that may be made by its manufacturer, is not guaranteed or endorsed by the publisher.

Copyright $\odot 2022$ Lui and Andrade. This is an open-access article distributed under the terms of the Creative Commons Attribution License (CC BY). The use, distribution or reproduction in other forums is permitted, provided the original author(s) and the copyright owner(s) are credited and that the original publication in this journal is cited, in accordance with accepted academic practice. No use, distribution or reproduction is permitted which does not comply with these terms. 